Submitted to Materials Science \& Engineering A , March, 2015

\title{
Aging effects on cyclic deformation and fatigue of extruded Mg-Gd-Y-Zr alloy
}

\author{
Shuai Dong ${ }^{1}$, Fenghua Wang ${ }^{1}$, Qu Wan ${ }^{2}$, Jie Dong $^{1}$, Wenjiang Ding ${ }^{1}$, Yanyao Jiang ${ }^{3 *}$ \\ ${ }^{1}$ National Engineering Research Center of Light Alloy Net Forming \& State Key Laboratory \\ of Metal Matrix Composites, Shanghai Jiao Tong University, Shanghai 200240, China \\ Phone: 021-34203052, Fax: 021-34202794, E-mail: jiedong@sjtu.edu.cn \\ ${ }^{2}$ AVIC Jiangxi Hongdu Aviation Industry Group Company Ltd., Nanchang 330001, China \\ ${ }^{3}$ University of Nevada, Department of Mechanical Engineering (312), Reno, NV 89557, \\ USA, Phone: 775-784-4510, Fax: 775-784-1701, E-mail: yjiang@unr.edu
}

*To whom correspondence should be addressed.

\begin{abstract}
The aging effects on the deformation and fatigue behavior of extruded Mg-8.0Gd-3.0Y-0.5Zr (GW83) magnesium (Mg) alloy were experimentally studied. The aging process significantly enhances the monotonic strengths under both tension and compression. The ductility under tension is unchanged but the elongation under compression is reduced due to the aging treatment. The cyclic stress-strain curve of the aged GW83 is much higher than that of the corresponding extruded state. The strain-life fatigue curve of the aged GW83 is similar to that of the extruded GW83, but the stress-life fatigue curve of the aged GW83 is much higher, indicating an improved fatigue strength due to the aging process. Similar to the other Mg alloys, a kink point in the strain-life fatigue curve was identified for the aged GW83 Mg alloy, and the kink point of a strain amplitude of $0.80 \%$ for the material demarcates the activation of bulk and persistent twinning/detwinning during cyclic deformation. The enhanced fatigue strength is discussed with respect to the observed fragmented persistent slip bands (PSBs) and the inhibition of microcracks by the precipitates in aged GW83.
\end{abstract}

Keywords: Cyclic deformation, Fatigue, Rare earth magnesium alloy, Aging effects 


\section{Introduction}

Due to the high specific strength and low density, magnesium $(\mathrm{Mg})$ alloys have been used in aerospace and automobile industry $[1,2]$. The addition of rare-earth (RE) element, such as Gd [3-16], Y [5-7, 12, 14, 16-29], La [7, 18, 19, 30], Nd [18, 19, 25-27], and Ce [18, 19, 31-33] in the Mg alloys offers weakened texture and improved mechanical properties as compared with the conventional $\mathrm{Mg}$ alloys. Artificial aging is an effective method to further enhance the strength of Mg-RE alloys by introducing hardening precipitates [3, 5, 12, 14, 24-27]. With the potential applications of Mg-RE alloys as load-bearing structural components, it is of great importance to investigate the influence of aging process on the cyclic deformation and fatigue properties of Mg-RE alloys.

Conventional wrought Mg alloys, such as AZ31 [34] and ZK60 [35], usually exhibit a strong basal texture with the $c$-axes of most grains perpendicular to the extrusion direction or rolling direction. The addition of rare-earth elements, such as $\mathrm{Gd}, \mathrm{Y}, \mathrm{Ce}$, and $\mathrm{Nd}$, in wrought $\mathrm{Mg}$ alloys can modify the texture that results in more random grain orientations. It was reported [36] that the RE elements in texture weakening of $\mathrm{Mg}$ alloys (1) modify the stacking fault energy (SFE) of the Mg matrix and (2) enhance the solute drag of grain boundaries and dislocations. Additionally, some RE elements, such as Y, can enhance the stability of partial dislocations of $\langle\mathrm{c}+\mathrm{a}\rangle$, which can facilitate the glide of $\langle\mathrm{c}+\mathrm{a}\rangle$ dislocations $[3,17,20,21]$. With a weakened basal texture and more activated non-basal slips, wrought Mg-RE alloys usually exhibit a near tension-compression symmetry in deformation.

Furthermore, the addition of $\mathrm{RE}$ elements in $\mathrm{Mg}$ alloys can offer enhanced mechanical strength, which can be achieved via precipitation hardening [12-14]. He et al. [14] studied the strengthening mechanisms of an extruded $\mathrm{Mg}-\mathrm{Gd}-\mathrm{Y}-\mathrm{Zr}$ alloy after artificial aging treatment. It was suggested that the remarkable precipitation strengthening can be attributable to the plate-shaped $\beta^{\prime}$ precipitate phases formed on the prismatic planes of $\alpha$-Mg matrix phase. The plate-shaped $\beta^{\prime}$ precipitates are vertical to the basal plane of the $\alpha$-Mg matrix and very thermally stable at $250^{\circ} \mathrm{C}$ [12], resulting in the most effective obstacles to the basal dislocation slips [37].

Studies [38-50] were conducted to understand the cyclic deformation and fatigue 
properties of Mg-RE alloys in the last decade. Wang et al. [48] suggested that for an extruded Mg-Gd-Y-Zr alloy, the material displayed near symmetric stress-strain hysteresis loops under fully reversed strain-controlled tension-compression cyclic loading. A kink point corresponding to a strain amplitude of $0.75 \%$ was detected in the strain-life fatigue curve. The kink point signifies a demarcation above which twinning deformation becomes significant. Wang et al. [47] also studied the fatigue damage development in extruded Mg-Gd-Y-Zr alloy. It was reported that at a high strain amplitude, the microcracks were initiated mainly at the grain boundaries (GBs). Microcrack coalescence played an important role in the final fatigue failure at a high strain amplitude. At a low strain amplitude, microcracks were nucleated at persistent slip bands (PSBs) and GBs but early crack growth often occurred along PSBs. A major part of fatigue life was spent on continuous initiation of microfatigue cracks. However, little work has been done to study the aging effects on the cyclic deformation, low-cycle fatigue (LCF) and fatigue damage of wrought $\mathrm{Mg}-\mathrm{RE}$ alloys.

Wrought $\mathrm{Mg}-\mathrm{Gd}-\mathrm{Y}-\mathrm{Zr}$ alloy is a typical high strength $\mathrm{Mg}-\mathrm{RE}$ alloy which displays a weaker texture, a higher strength, and improved ductility as compared with the conventional $\mathrm{Mg}$ alloys. Most of the wrought Mg-RE alloys are used after aging treatment as structural materials. Therefore, it is important to understand the low-cycle fatigue performance and cyclic plastic deformation of Mg-RE alloys with the aging effects. In the present work, an extruded GW83 alloy after artificial aging treatment was used to study the aging effects on the cyclic deformation, the LCF properties, and fatigue damage under fully reversed strain-controlled tension-compression loading along the extrusion direction.

\section{Material and experiment}

\subsection{Material and Specimen}

A billet with a nominal composition of $\mathrm{Mg}-8.0 \mathrm{Gd}-3.0 \mathrm{Y}-0.5 \% \mathrm{Zr}(\mathrm{wt} \%)$ and a diameter of $180 \mathrm{~mm}$ was prepared by semi-continuous casting. The billet was extruded to a bar with a diameter of $45 \mathrm{~mm}$ at $460^{\circ} \mathrm{C}$ and an extrusion ratio of $16: 1$ after solution treated at $520^{\circ} \mathrm{C}$ for eight hours. Before testing, the extruded bar was artificially aged at $225^{\circ} \mathrm{C}$ for 10 hours (T5). In the subsequent discussions, the hot-extruded GW83 will be referred to as 
"as-extruded" and the material after the aging process will be referred to as "aged." The initial microstructure, mechanical properties, LCF properties, and fatigue damage development of as-extruded GW83 were reported in previously published papers [47, 48]. Some of these published experimental results were cited in this work in order to compare the experimental results of the aged material with these of the as-extruded GW83 alloy.
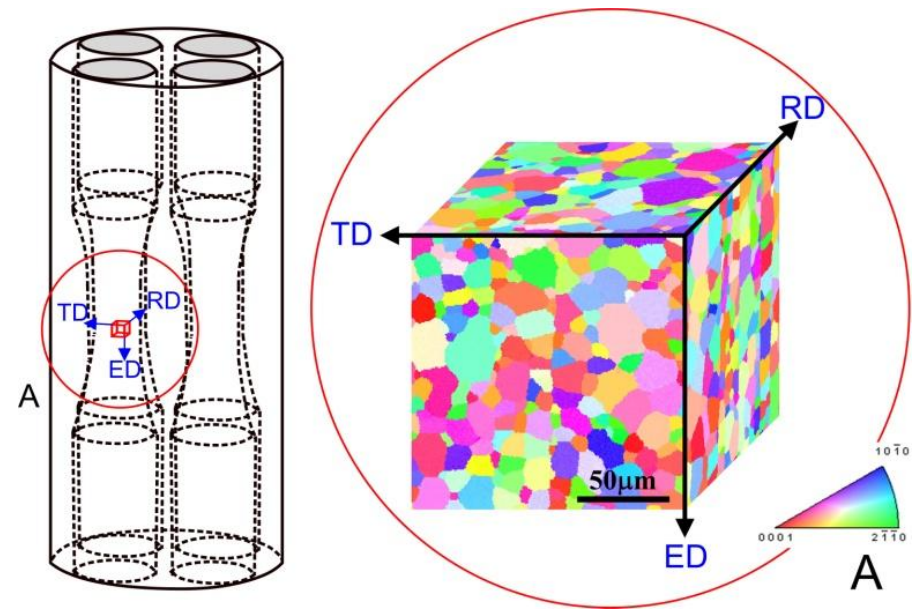

(a)
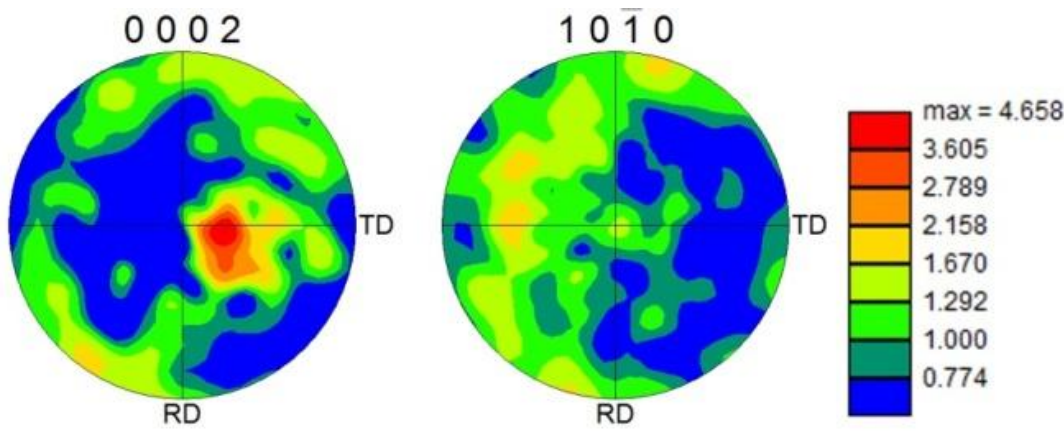

(b)

Fig. 1. Aged GW83 alloy: (a) testing specimens cut from extruded bar and three-dimensional stereography of initial microstructure measured by EBSD, (b) (0002) and (10-10) pole figures measured by EBSD on the RD-TD plane.

As shown in Fig. 1a, four solid cylindrical dog-bone shaped testing specimens with a diameter of $10.0 \mathrm{~mm}$ and a gage length of $12.5 \mathrm{~mm}$ were machined for the monotonic and fully reversed strain-controlled cyclic loading experiments. The axial direction of the testing specimen was aligned parallel to the extrusion direction. Fig. 1a also shows the three-dimensional stereography of the initial microstructure measured by electron 
back-scattered diffraction (EBSD) for the aged GW83 alloy. Three planes perpendicular to the extrusion direction (ED), the radial direction (RD), and the transverse direction (TD) were examined. On all the three planes, equiaxial grains with an average size of $25 \mu \mathrm{m}$ were observed. No twins were detected in the aged state. Fig. 1b presents the (0002) and (10-10) pole figures obtained from the EBSD scan on the RD-TD plane of the aged GW83 alloy. It can be seen that the aged GW83 exhibits a weakened texture similar to that of the as-extruded GW83 [48]: the $c$-axes of grains have a weak tendency to orient along the direction parallel to the ED direction. The intensity of (0002) pole is much lower than that of the conventional extruded Mg alloys.

\subsection{Experiments}

Monotonic deformation and fully reversed strain-controlled tension-compression cyclic loading experiments were conducted using an Instron 8808 hydraulic servo fatigue machine in ambient air. An extensometer with a gage length of $12.7 \mathrm{~mm}$ and a range of $\pm 40 \%$ was used for monotonic loading experiments to measure the axial strain. For fully reversed strain-controlled cyclic experiments, an extensometer with a gage length $12.7 \mathrm{~mm}$ and a range of $\pm 10 \%$ was used. The strain amplitude ranges from $5 \%$ to $0.3 \%$, and the loading frequency ranges from $0.2 \mathrm{~Hz}$ to $10 \mathrm{~Hz}$ dependent on the strain amplitude. To examine the microstructure of the specimens after monotonic and cyclic loading by EBSD, a cylindrical sample was cut away from the fracture area but within the gage section of the testing specimen. EBSD scans were performed with TSL data acquisition software on an area of $250 \mu \mathrm{m} \times 250 \mu \mathrm{m}$ with a step size of $0.5 \mu \mathrm{m}$. High-magnified EBSD areas are used to show the featured local microstructure. The EBSD data was analyzed using TSL OIM software.

For studying the fatigue damage evolution, dog-bone shaped plate specimens having a rectangular cross section of $4.5 \mathrm{~mm} \times 4.0 \mathrm{~mm}$ with a gage length of $8.0 \mathrm{~mm}$ were machined from the aged GW83 bar to observe the crack topography on the ED-TD plane. The surfaces of the tested specimens were pre-etched by acetic-picric solution, and examined by high resolution SEM (Hitachi S-4700) after fatigue testing. More detailed experimental process on fatigue damage testing can be found in previous work [47]. 


\section{Experimental results and discussion}

\subsection{Monotonic tension and compression}

Fig. 2a shows the stress-strain curves obtained from monotonic tension and compression for both as-extruded and aged GW83 alloys. The compressive stress and strain are reported in their absolute values in order to compare the compression results to the tension results. Fig. $2 b$ presents the initial parts of the stress-plastic strain curves. The plastic strain is defined as the total true stain subtracted by its linear part which is equal to the stress divided by the initial elasticity modulus. Table 1 lists the mechanical properties of both as-extruded and aged GW83 along ED.

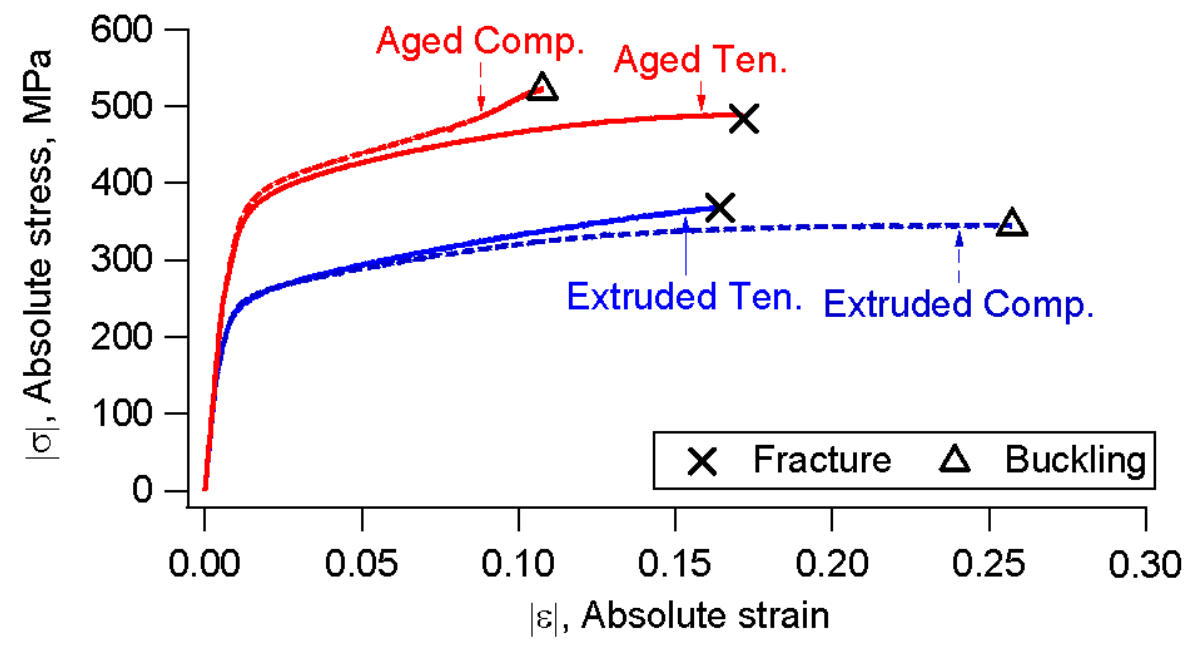

(a)

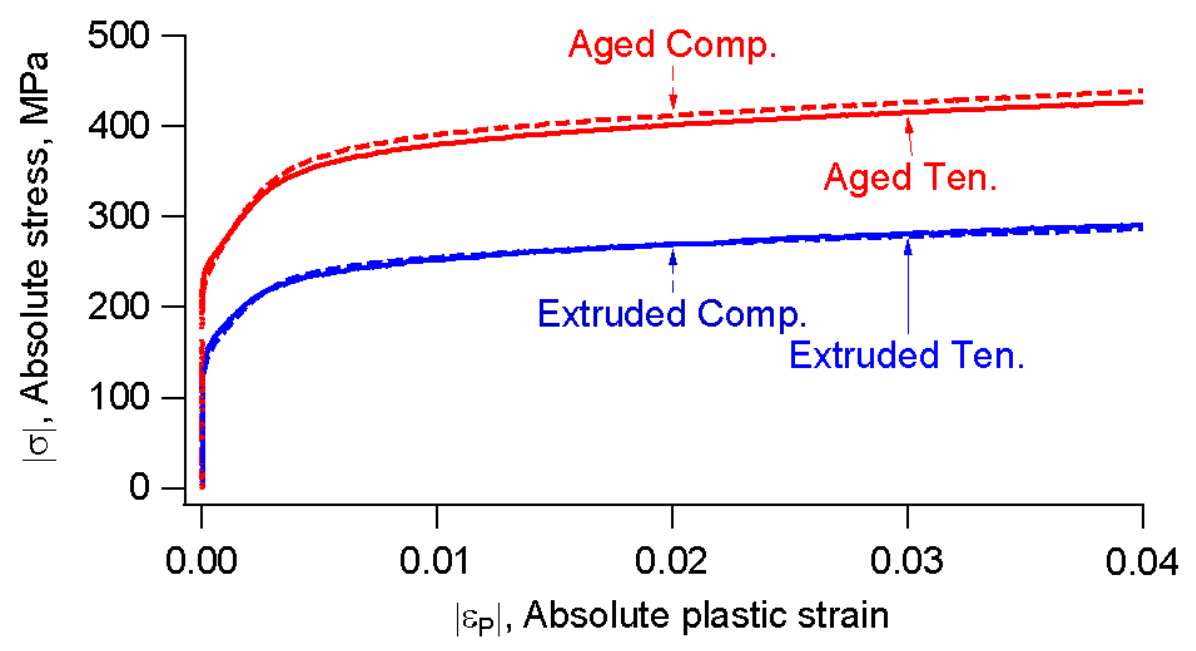

(b)

Fig. 2. Stress-strain curves of as-extruded and aged GW83 alloys under monotonic tension and compression: (a) stress-strain curves, (b) stress-plastic strain curves (results of as-extruded GW83 alloy are taken from Ref.[48]). 
Table 1 Mechanical properties of as-extruded and aged GW83 alloys along extrusion direction (results of as-extruded GW83 alloy are taken from Ref.[48]).

\begin{tabular}{lll}
\hline & Aged & As-extruded \\
\hline Elasticity modulus, $E_{0}$ & $43.7 \mathrm{GPa}$ & $43.6 \mathrm{GPa}$ \\
Elastic limit, $\sigma_{e t}\left(\right.$ or $\left.\sigma_{e c}\right)$ & $207 \mathrm{MPa}$ & $96 \mathrm{MPa}$ \\
$0.2 \%$ offset-yield stress in tension, $\sigma_{y t 0.2}$ & $308 \mathrm{MPa}$ & $205 \mathrm{MPa}$ \\
$0.2 \%$ offset-yield stress in compression, $\sigma_{y c 0.2}$ & $309 \mathrm{MPa}$ & $203 \mathrm{MPa}$ \\
Ultimate strength under tension, $S_{u t}$ & $413 \mathrm{MPa}$ & $307 \mathrm{MPa}$ \\
Fracture stress under tension, $\sigma_{f t}$ & $489 \mathrm{MPa}$ & $367 \mathrm{MPa}$ \\
Elongation under tension, $e_{f t}$ & $17.2 \%$ & $16.4 \%$ \\
\hline
\end{tabular}

From Fig. 2a it can be seen that the stress-strain curves of both as-extruded and aged GW83 alloy exhibit a near tension-compression symmetry. The addition of Gd and Y in the wrought $\mathrm{Mg}$ alloys leads to a weakened basal-texture. Due to the random orientation of grains in GW83 alloy, the twinning volume fraction is very small under both tension and compression, resulting in symmetric mechanical behavior [48].

The monotonic stress-strain curves of both as-extruded and aged GW83 can be divided into three regimes: elastic deformation, microyielding, and macroyielding. When the stress exceeds the elastic limit, microyielding occurs, which can be mainly ascribed to the activation of basal slips in favorably orientated grains. The elastic limit under monotonic tension is identical to that under monotonic compression for the same material. For as-extruded GW83, the elastic limit for both monotonic tension and compression is approximate 96MPa. For aged GW83, the elastic limit is dramatically increased to $207 \mathrm{MPa}$ due to the precipitates introduced by the aging treatment. It should be noticed that the elastic limit concept is defined for the material under monotonic loading and it was obtained using a very small plastic strain offset (approximately $2 \times 10^{-5}$ ). Cyclic loading with fatigue damage may alter the range of stress corresponding to pure elastic deformation. 
The strengthening effect due to precipitates can also be seen in the macroyielding stress and the ultimate strength. The aging process increases the macroyielding stress from $205 \mathrm{MPa}$ to $308 \mathrm{MPa}$ under monotonic tension and from 203MPa to 309MPa under monotonic compression. Moreover, the ultimate strength and the fracture stress in tension are increased by $106 \mathrm{MPa}$ and $122 \mathrm{MPa}$, respectively. However, the elongations of as-extruded and aged GW83 are similar. They are $16.4 \%$ and $17.2 \%$, respectively.

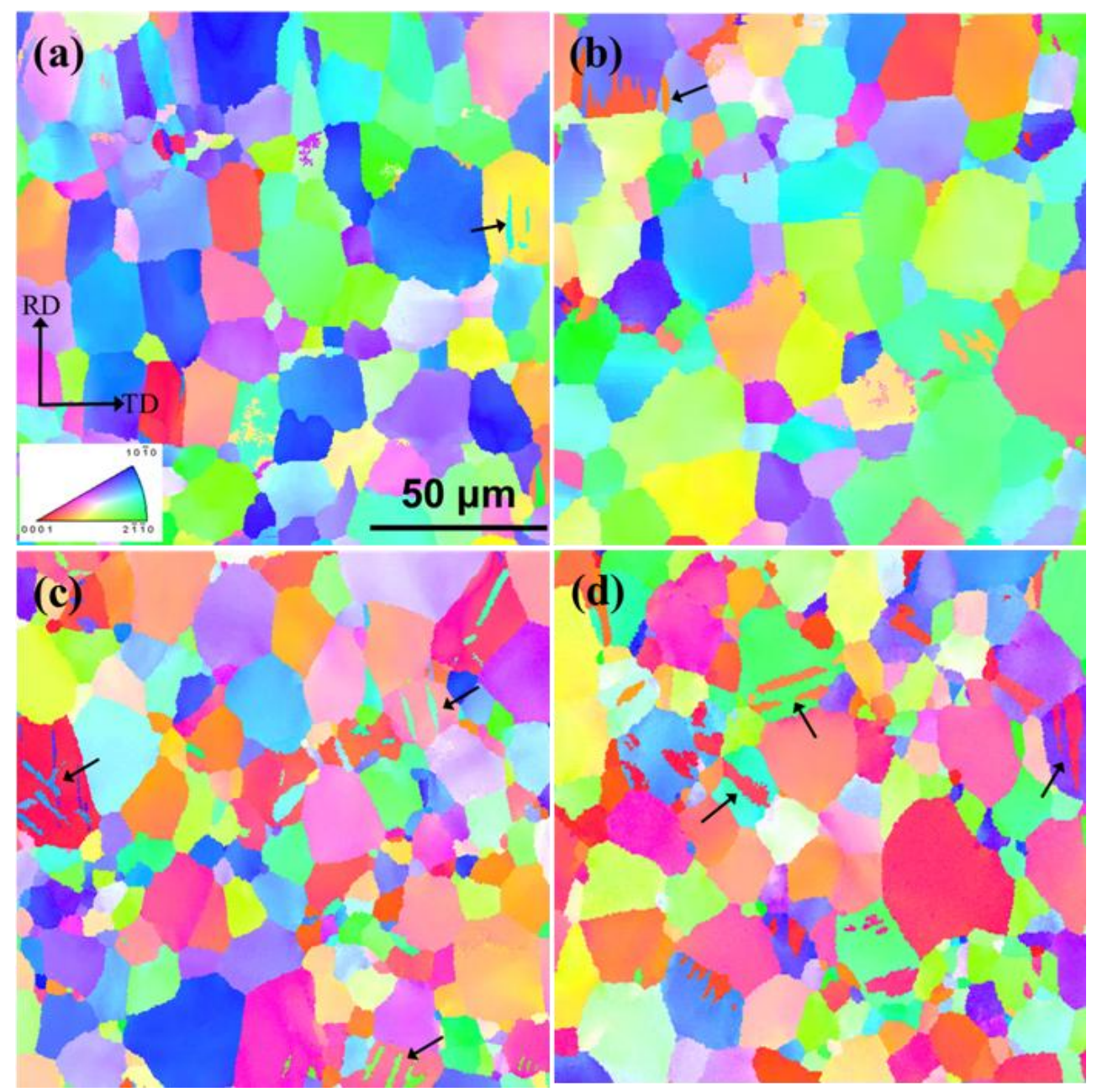

Fig. 3. The inverse pole figure (IPF) maps measured by EBSD for as-extruded and aged GW83 under monotonic deformation: (a) 5\% tension of as-extruded, (b) 5\% compression of as-extruded, (c) $5 \%$ tension of aged, (d) $5 \%$ compression of aged. (Black arrows point to the tension twins).

To understand the aging effect on tension twinning, EBSD scans were conducted at a tension strain of 5\% and a compression strain of 5\% for both as-extruded and aged GW83 and Fig. 3 shows the EBSD results. For as-extruded GW83, as shown by the black arrows 
in Fig. 3a and Fig. 3b, tension twins can be detected under both monotonic tension and compression. The $c$-axes of grains have a weak tendency to orient parallel to the ED direction. Therefore, tension twinning can be activated under both monotonic tension and compression. These tension twins are confirmed to have a $86.3^{\circ}$ misorientation angle with respect to the $<2-1-10>$ rotation axis. However, the amounts of tension twins shown in Fig. 3 are very small.

The IPF maps of aged GW83 at a tension strain of 5\% and a compression strain of $5 \%$ are presented in Fig. 3c and 3d, respectively, and tension twins can be found under both tension and compression with a similar amount. Compared to as-extruded GW83, more tension twins are observed in aged GW83 at the same tension/compression strain, which is mainly due to the precipitates introduced by the aging process. The precipitates in aged GW83 can impede dislocation slips and result in local stress concentrations around these precipitates. These sites accompanied by the increased local stress can induce twin nucleation [51]. Therefore, the precipitates can promote twin nucleation [51, 52] and more twins can be observed in aged GW83. However, the twin volume fractions (TVFs) in Fig. $3 \mathrm{c}$ and $3 \mathrm{~d}$ are still very small, approximately $3 \%$. The similar and small TVFs under monotonic tension and compression indicates that tension twinning is not the dominate deformation mode, and the result is the observed near tension-compression symmetry in deformation.

\subsection{Cyclic deformation}

Fig. 4a shows the stress-strain hysteresis loops obtained from fully reversed strain-controlled cyclic loading experiments for aged GW83 at four strain amplitudes: 5\%, $2 \%, 0.6 \%$, and $0.35 \%$. In order to investigate the evolution with loading cycles, the stress-strain hysteresis loops of the first 10 cycles, the cycle at half fatigue life and the cycle close to fatigue life are presented for a selected strain amplitude. 


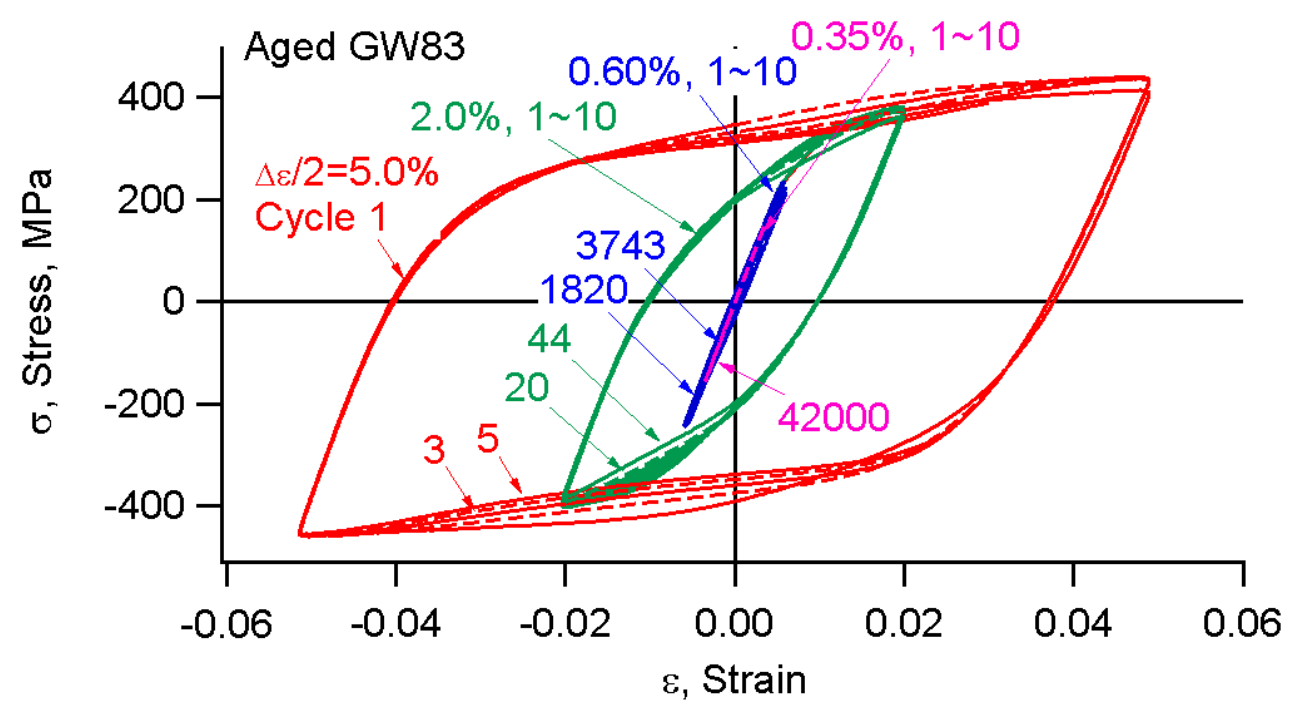

(a)

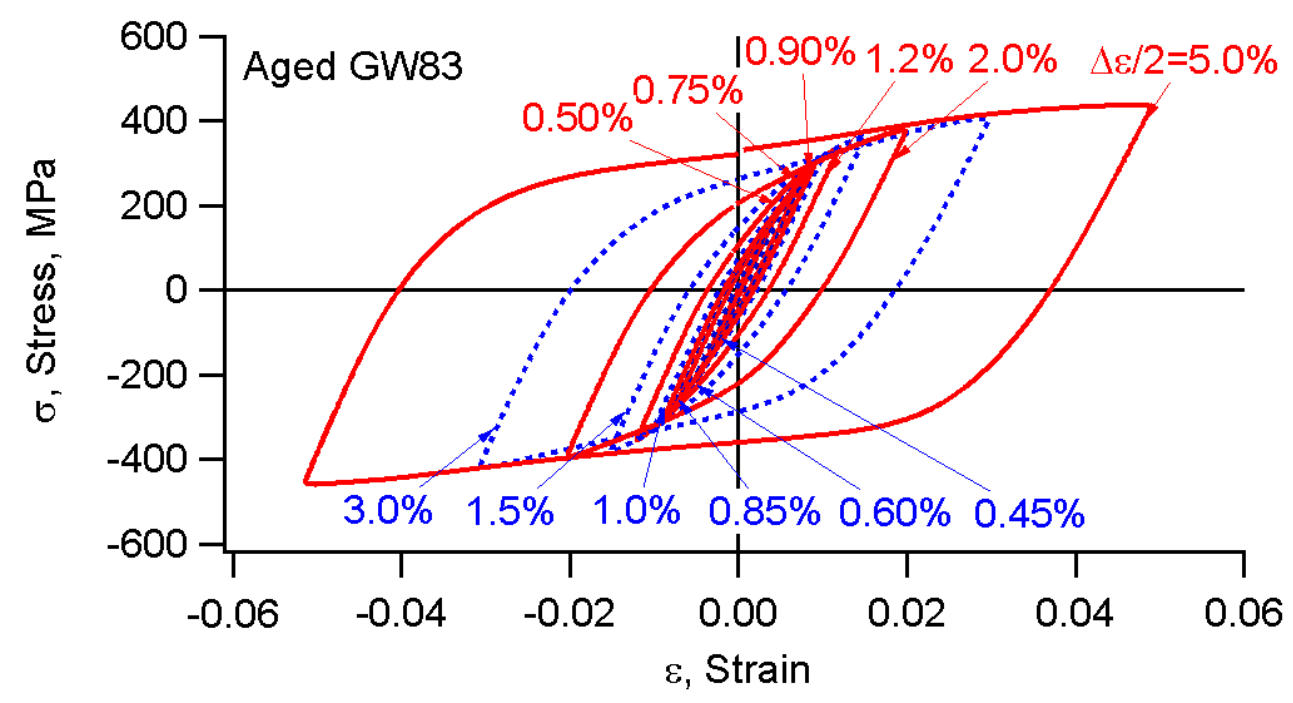

(b)

Fig. 4. (a) Stress-strain hysteresis loops at the strain amplitudes of $0.35 \%, 0.60 \%, 2 \%$ and 5\%, (b) Stabilized stress-strain hysteresis loops at half-life cycles with the strain amplitudes ranging from $0.45 \%$ to $5.0 \%$ for aged GW83 alloys.

At a strain amplitude of 5\% for the first loading cycle, both the upper branch and lower branch of the stress-strain hysteresis loop exhibit a concave-down shape and the stress-strain hysteresis loop exhibits a symmetric shape. After the second loading cycle till fatigue fracture, the shape of the stress-strain hysteresis loop evolves from a concave-down shape to a sigmoidal shape, indicating the occurrence of twinning-detwinning. Due to weak texture in aged GW83, twinning-detwinning can be activated in both tension and compression 
reversals. At a strain amplitude of 5\%, insignificant twinning-detwinning occurs during the first loading cycle but it becomes more active with increasing loading cycles. This phenomenon was also reported in the cyclic deformation of as-extruded GW83 [48]. It is interesting to notice that the peak stresses keep almost unchanged after the second loading cycle. From Fig. 4a it can be seen that the cyclic stress-strain response at the strain amplitude of $2 \%$ has a similar behavior to that of $5 \%$. Twinning-detwining process takes part in the cyclic plastic deformation and it becomes more significant with increasing loading cycles.

When the strain amplitude is $0.60 \%$, the maximum stress and the minimum stress are slightly higher than the linear elastic limit, indicating that microyielding occurs at this strain amplitude. The stress-strain hysteresis loops are symmetric and keep almost unchanged with increasing loading cycles. When the strain amplitude is $0.35 \%$, both the maximum stress and the minimum stress are smaller than the elastic limit. The stress-strain hysteresis loops are symmetric and the bulk deformation is elastic. However, it can be found from Table 2 that at a strain amplitude of $0.35 \%$, both the plastic strain amplitude and the plastic strain energy density per loading cycle, $\Delta \mathrm{W}^{\mathrm{p}}$, are detectable. This indicates that micro-plastic deformation may occur locally at a strain amplitude of $0.35 \%$ during fatigue loading.

The stress-strain hysteresis loops corresponding to half fatigue lives are taken to be the stabilized hysteresis loops in the present study. Fig. $4 \mathrm{~b}$ presents the stabilized stress-strain hysteresis loops with the strain amplitudes ranging from $0.45 \%$ to $5 \%$ for aged GW83 alloy. It can be seen that the stabilized stress-strain hysteresis loops of aged GW83 display similar features to these of as-extruded GW83 [48]. When the strain amplitudes are lower than $0.85 \%$, the upper branch and lower branch of loops are nearly fully symmetric. When the strain amplitudes are higher than $0.85 \%$, slightly asymmetry is observed.

Despite the similar features of the stabilized stress-strain hysteresis loops for as-extruded and aged GW83, the aging process has a manifest strengthening effect on the cyclic deformation. Fig. 5 presents the variation of stress amplitudes with the number of loading cycles for as-extruded and aged GW83 alloys at three representative strain amplitudes. For 
a strain amplitude of $0.35 \%$, the stress amplitude of aged GW83 is slightly higher than that of as-extruded GW83. With the increasing strain amplitudes, the strengthening effect of aging treatment becomes more obvious. At strain amplitudes of $0.6 \%$ and $2 \%$, the stress amplitudes of the stabilized hysteresis stress-strain loops for aged GW83 are increased by about $37 \mathrm{MPa}$ and $105 \mathrm{MPa}$, respectively, compared to the as-extruded GW83.

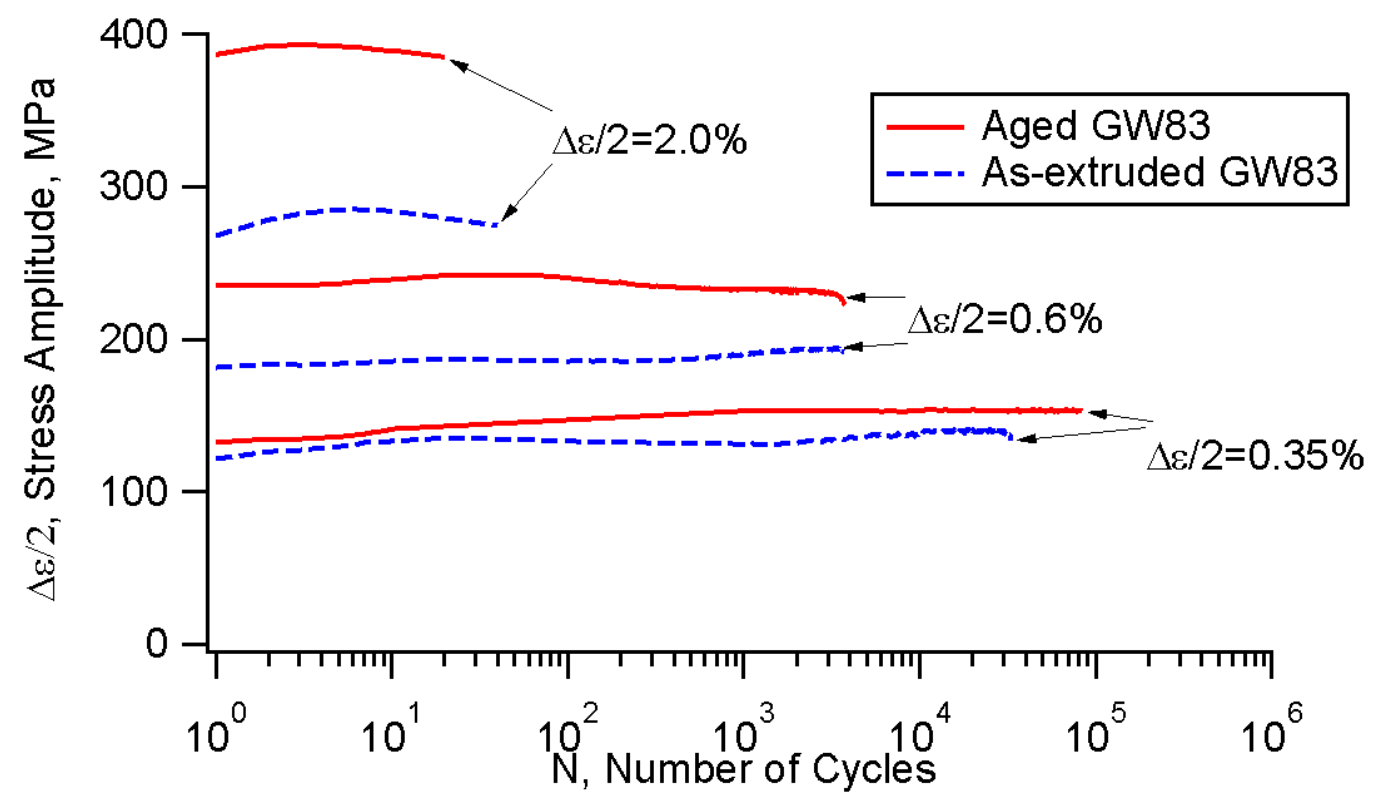

Fig. 5. Variation of stress amplitude with the number of loading cycles for as-extruded and aged GW83 alloys (results of as-extruded GW83 alloy are from Ref.[48]). 


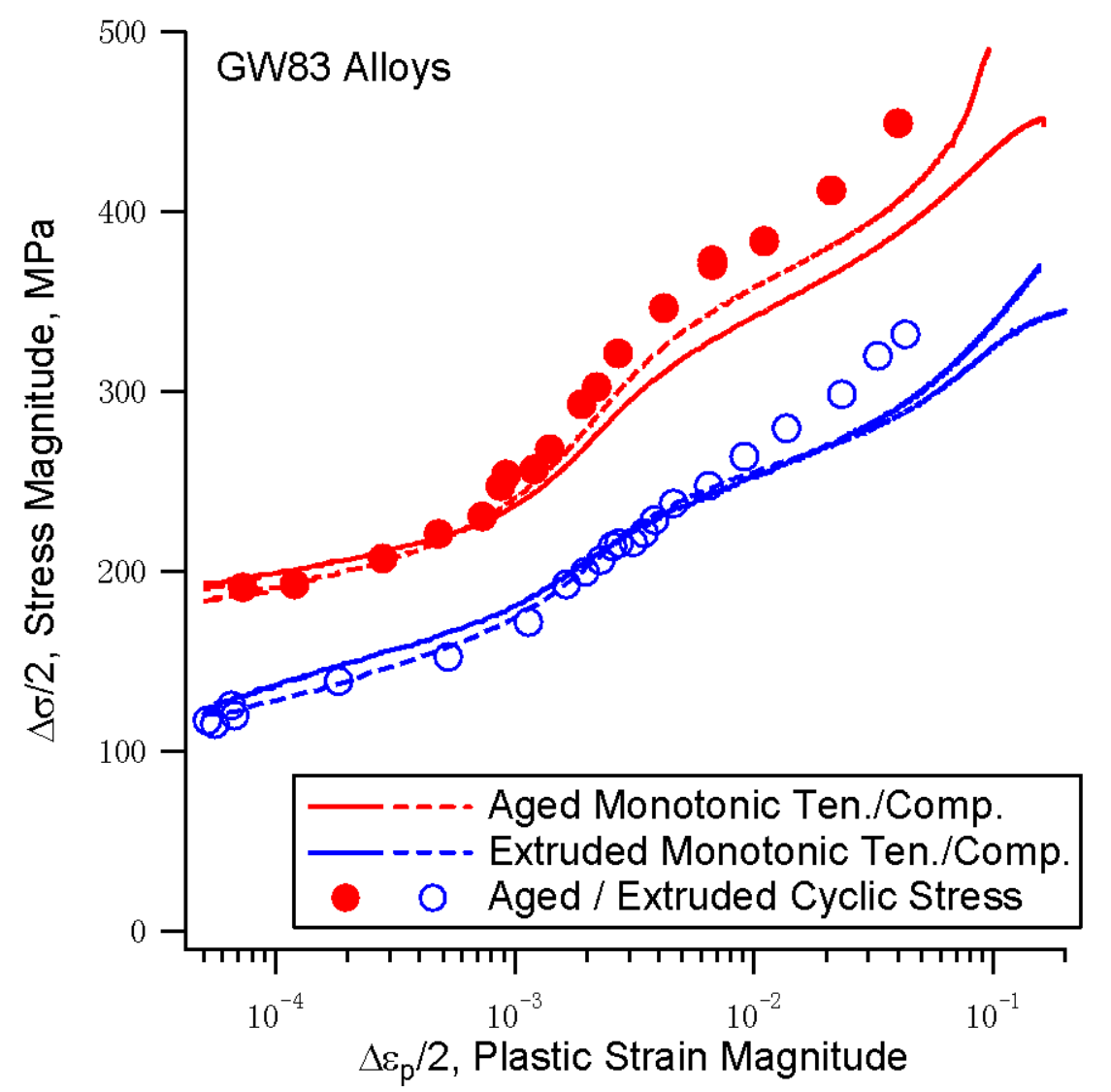

Fig. 6. Cyclic stress-plastic strain curves (CSPSC) for as-extruded and aged GW83 alloys (results of as-extruded GW83 alloy are from Ref.[48]).

Fig. 6 presents the cyclic stress-plastic strain curves (CSPSC) for as-extruded and aged GW83 together with the monotonic tension and monotonic compression stress-plastic strain curves. Strengthening effect due to aging treatment can be obviously seen: for the same plastic strain magnitude, the stress magnitude of aged GW83 is significantly higher than that of as-extruded GW83. It was reported that for as-extruded GW83 when the stress magnitude is less than $237 \mathrm{MPa}$, the CSPSC is practically identical to the monotonic tension and compression stress-plastic strain curves [48]. A similar observation is made for aged GW83. Fig. 6 reveals that the CSPSC of aged GW83 is very close to the monotonic stress-strain curves when the stress magnitude is less than $231 \mathrm{MPa}$, signifying little cyclic hardening or softening. When the strain magnitude is above $231 \mathrm{MPa}, \mathrm{CSPSC}$ is higher than the monotonic stress-plastic strain curves, indicating cyclic hardening. 


\subsection{Fatigue}

The fatigue results of aged GW83 obtained from fully reversed strain-controlled tension-compression experiments along the extrusion direction are summarized in Table 2. The stress and strain quantities reported in Table 2 are taken from the stress-strain hysteresis loops at approximately half fatigue lives. With decreasing strain amplitudes, the fatigue lives of aged GW83 alloy increase, but the mean stresses keep almost unchanged, ranging from $-10 \mathrm{MPa}$ to $0 \mathrm{MPa}$. The minimal mean stress for aged GW83 is due to the near symmetric stress-strain hysteresis loops resulted from the weakened texture and the resistance of rare earth elements on the occurrence of twinning.

Table 2 Fatigue results of aged GW83 alloy under fully reversed strain-controlled tension-compression the along extrusion direction.

\begin{tabular}{|c|c|c|c|c|c|c|}
\hline Spec ID & $\begin{array}{c}\Delta \varepsilon / 2 \\
(\%)\end{array}$ & $\begin{array}{c}\Delta \varepsilon_{p} / 2 \\
(\%)\end{array}$ & $\begin{array}{l}\Delta \sigma / 2 \\
(\mathrm{MPa})\end{array}$ & $\begin{array}{c}\sigma_{\mathrm{m}} \\
(\mathrm{MPa})\end{array}$ & $\begin{array}{c}\Delta W^{p} \\
\left(\mathrm{MJ} / \mathrm{m}^{3}\right)\end{array}$ & $\begin{array}{c}N_{\mathrm{f}} \\
\text { (cycle) }\end{array}$ \\
\hline 83IIIAUN06 & 5.0 & 0.04 & 449.0 & -9.77 & 55.15 & 5 \\
\hline 83IIIAUN07 & 3.0 & 0.02 & 411.7 & -4.80 & 23.59 & 14 \\
\hline 83IIIAUN03 & 2.0 & 0.01 & 383.6 & -7.84 & 11.11 & 44 \\
\hline 83IIIAUN22 & 2.0 & 0.01 & 383.3 & -7.19 & 11.35 & 31 \\
\hline 83IIIAUN08 & 1.5 & 0.007 & 372.7 & -9.55 & 6.08 & 60 \\
\hline 83IIIAUN12 & 1.5 & 0.007 & 370.0 & -10.05 & 6.08 & 66 \\
\hline 83IIIAUN11 & 1.2 & 0.004 & 346.1 & -8.00 & 3.41 & 140 \\
\hline 83IIIAUN04 & 1.0 & 0.003 & 321.0 & -5.71 & 1.85 & 260 \\
\hline 83IIIAUN21 & 0.9 & 0.002 & 302.4 & -7.11 & 1.33 & 400 \\
\hline 83IIIAUN16 & 0.85 & 0.002 & 292.7 & -3.46 & 1.07 & 640 \\
\hline 83IIIAUN09 & 0.75 & 0.001 & 267.6 & -7.39 & 0.75 & 1,200 \\
\hline 83IIIAUN05 & 0.6 & 0.0007 & 230.4 & -8.69 & 0.34 & 3,743 \\
\hline 83IIIAUN13 & 0.5 & 0.00028 & 207.0 & -7.97 & 0.11 & 15,650 \\
\hline 83IIIAUN14 & 0.45 & 0.00012 & 192.5 & -2.46 & 0.02 & 28,400 \\
\hline 83IIIAUN17 & 0.45 & 0.00010 & 191.0 & -4.07 & 0.014 & 26,600 \\
\hline 83IIIAUN15 & 0.4 & $4.19 \mathrm{e}-05$ & 175.3 & -3.78 & 0.002 & 37,500 \\
\hline 83IIIAUN18 & 0.35 & $1.38 \mathrm{e}-05$ & 152.9 & -2.49 & 0.0003 & 84,000 \\
\hline 83IIIAUN23 & 0.32 & -- & 140.0 & -- & ---- & $>229,942$ \\
\hline 83IIIAUN20 & 0.30 & $1.06 \mathrm{e}-05$ & 131.7 & -1.63 & 0.0001 & $>343,412$ \\
\hline
\end{tabular}




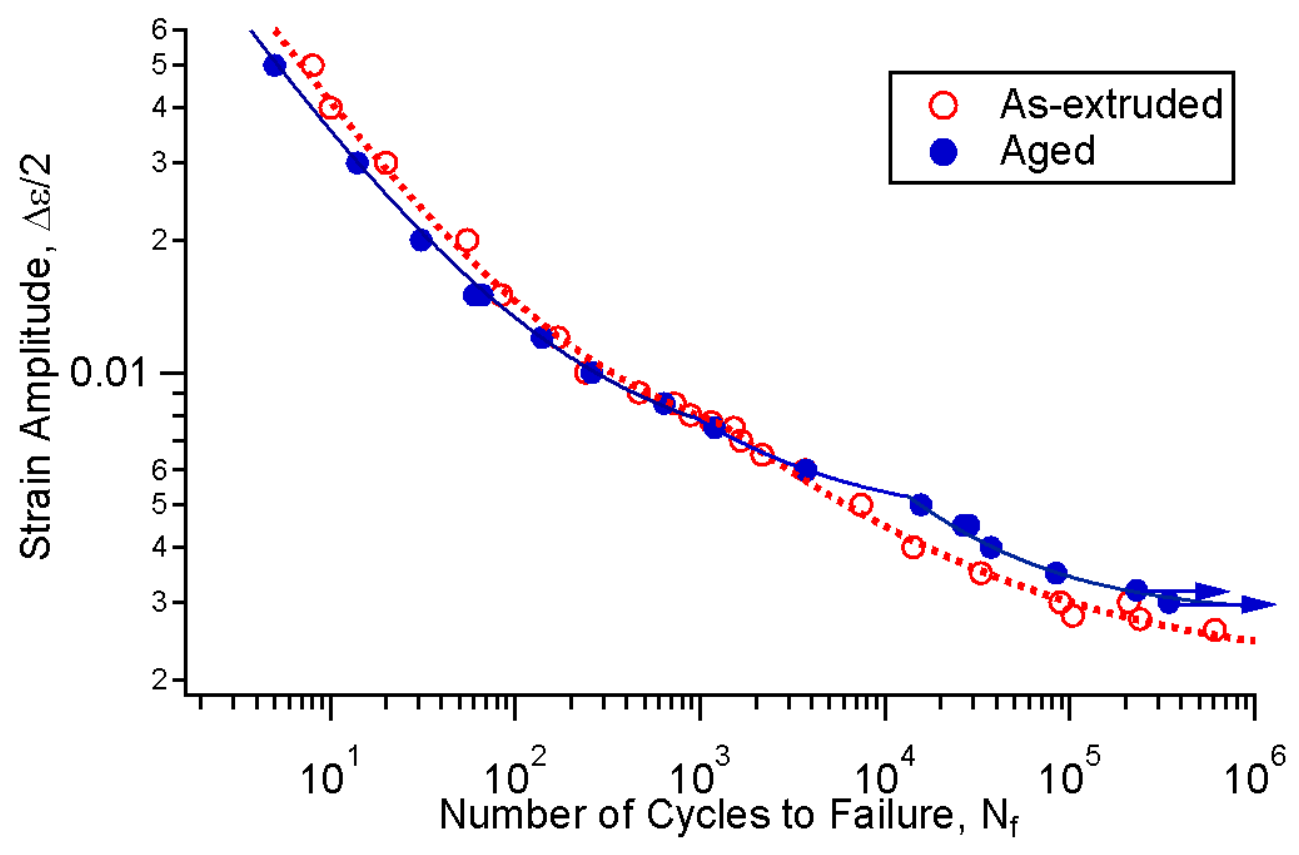

(a)

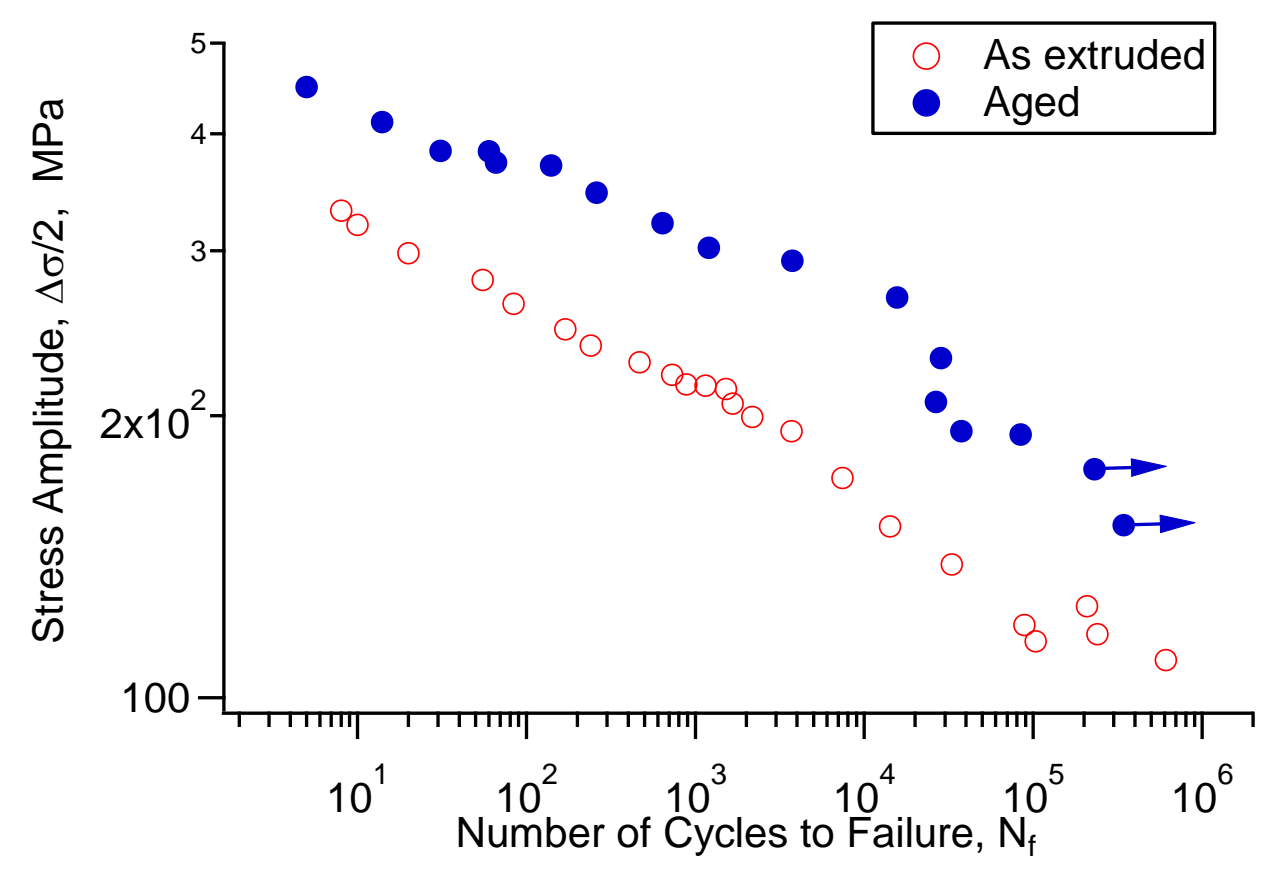

(b)

Fig. 7. Fatigue life curves for as-extruded and aged GW83: (a) strain-life curves, (b) stress-life curves (results of as-extruded GW83 alloy are from Ref.[48]).

Fig. 7 shows the strain-life and stress-life curves of both as-extruded and aged GW83. Each point represents one fatigue experiment. An arrow after a data point designates a run-out experiment. The following three-parameter equation is used to describe the 
strain-life curves:

$$
\left(\frac{\Delta \varepsilon}{2}-\varepsilon_{0}\right)^{\xi} N_{f}=C
$$

where $\Delta \varepsilon / 2$ is the strain amplitude and $N_{f}$ is the number of cycles to failure. The remaining three parameters $\varepsilon_{0}, \xi$ and $C$ are constants obtained by best fitting the experimental data.

It was reported that there existed a kink point in the strain-life curves for AZ31B [53], AZ61 [54], ZK60 [55, 56], and extruded GW83 [48] alloys. The kink point represents a demarcation line above which twinning-detwinning process is a significant plastic deformation mechanism in cyclic deformation. When the strain amplitude is below the kink point, dislocation slips dominate the cyclic plastic deformation. From Fig. 7a it can be seen that such a kink point exists for both as-extruded and aged GW83. For as-extruded GW83, it was reported [48] that the strain amplitude corresponding to this kink point is $0.75 \%$. For aged GW83, the strain amplitude corresponding to the kink point is slightly increased to $0.8 \%$.

A careful observation reveals that there exists another kink point with a strain amplitude of approximate $0.5 \%$ in the strain-life curve of aged GW83. When the strain amplitude is below $0.5 \%$, the stress-strain hysteresis loops are fully symmetric and the bulk cyclic deformation is elastic. However, results listed in Table 2 indicate that both the plastic strain amplitude and the plastic strain energy density per loading cycle, $\Delta \mathrm{W}^{\mathrm{p}}$, are measurable, which indicates that micro plastic deformation occurs during cyclic loading. Therefore, the kink point corresponding to a strain amplitude of $0.5 \%$ may represent the transition from micro-plastic deformation to macro-plastic deformation.

Results shown in Fig. 7a reveals that when the strain amplitude is larger than $0.80 \%$, the fatigue life of as-extruded is similar to that of aged GW83. When the strain amplitude is less than $0.80 \%$, aged GW83 exhibits a slightly longer fatigue life at an identical strain amplitude. From the stress-life results shown in Fig. 7b, it can be seen that the material is significantly strengthened by precipitates introduced by aging treatment. Under the same stress amplitudes, aged GW83 has much longer fatigue lives than as-extruded GW83. 
In order to explore further the cyclic plastic deformation mechanisms at the strain amplitudes near the upper kink point in the strain-life curve of aged GW83, EBSD scans were taken on the specimens after fatigue testing at the strain amplitudes above and below the upper kink point. Fig. 8 presents the microstructures measured by EBSD for aged GW83 alloy after fatigue testing at strain amplitudes of $0.6 \%$ and $2 \%$. Hexagonal sketches in Fig. $8 \mathrm{~b}$ indicate the orientations of the grains. It can be found that when the strain amplitude is $0.6 \%$, no residual twins can be detected, indicating that slips, mainly basal slips, dominate the cyclic plastic deformation. When the strain amplitude is $2 \%$, residual twins are detectable inside the grains, signifying the activation of the twinning-detwinning process.
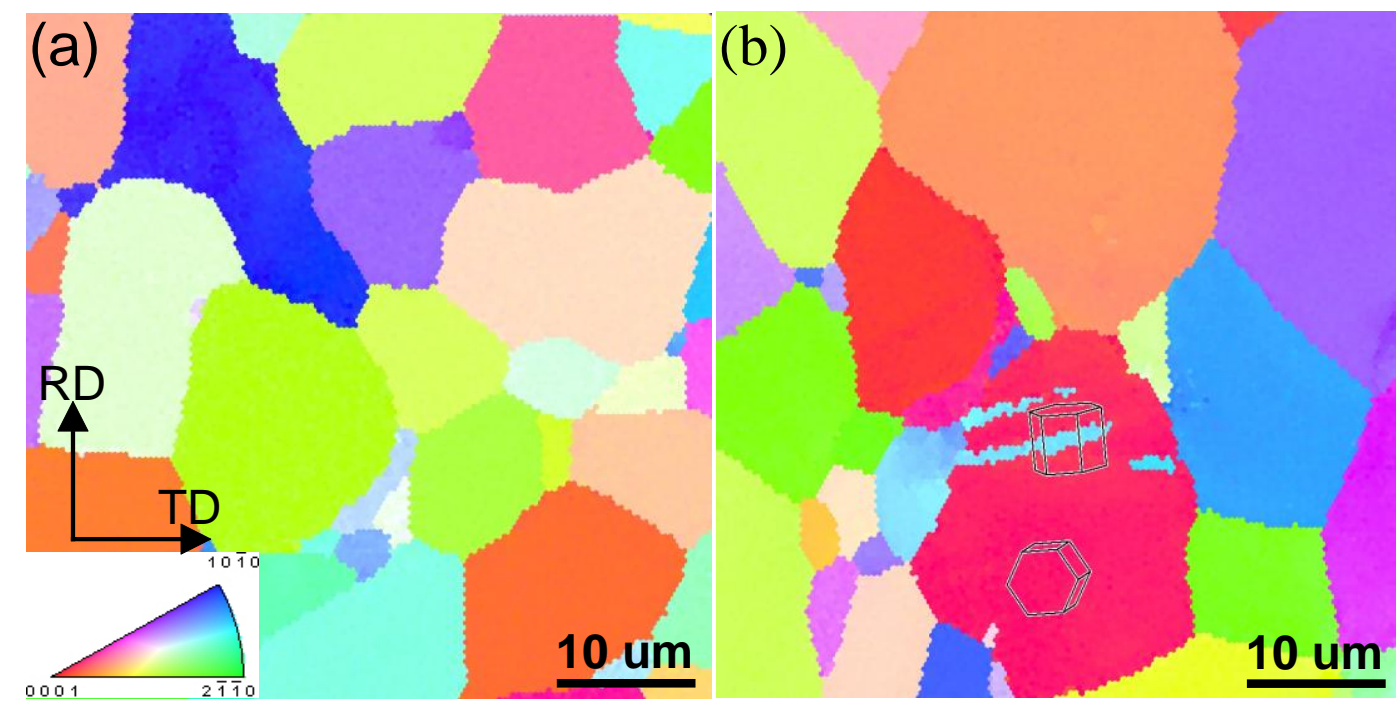

Fig. 8. IPF maps measured by EBSD of the aged specimens after fatigue testing at the strain amplitudes of: (a) $\Delta \varepsilon / 2=0.60 \%$; (b) $\Delta \varepsilon / 2=2.0 \%$

\subsection{Fatigue damage}

It has been mentioned that for extruded GW83 alloy, when the strain amplitudes are smaller than $0.80 \%$, the aging process can improve the fatigue properties. For example, at a strain amplitude of $0.5 \%$, the fatigue lives of as-extruded and aged GW83 are 7,420 cycles and 15,650 cycles, respectively. Therefore, it is of interest to investigate the aging effect on the fatigue damage on GW83 alloy. 

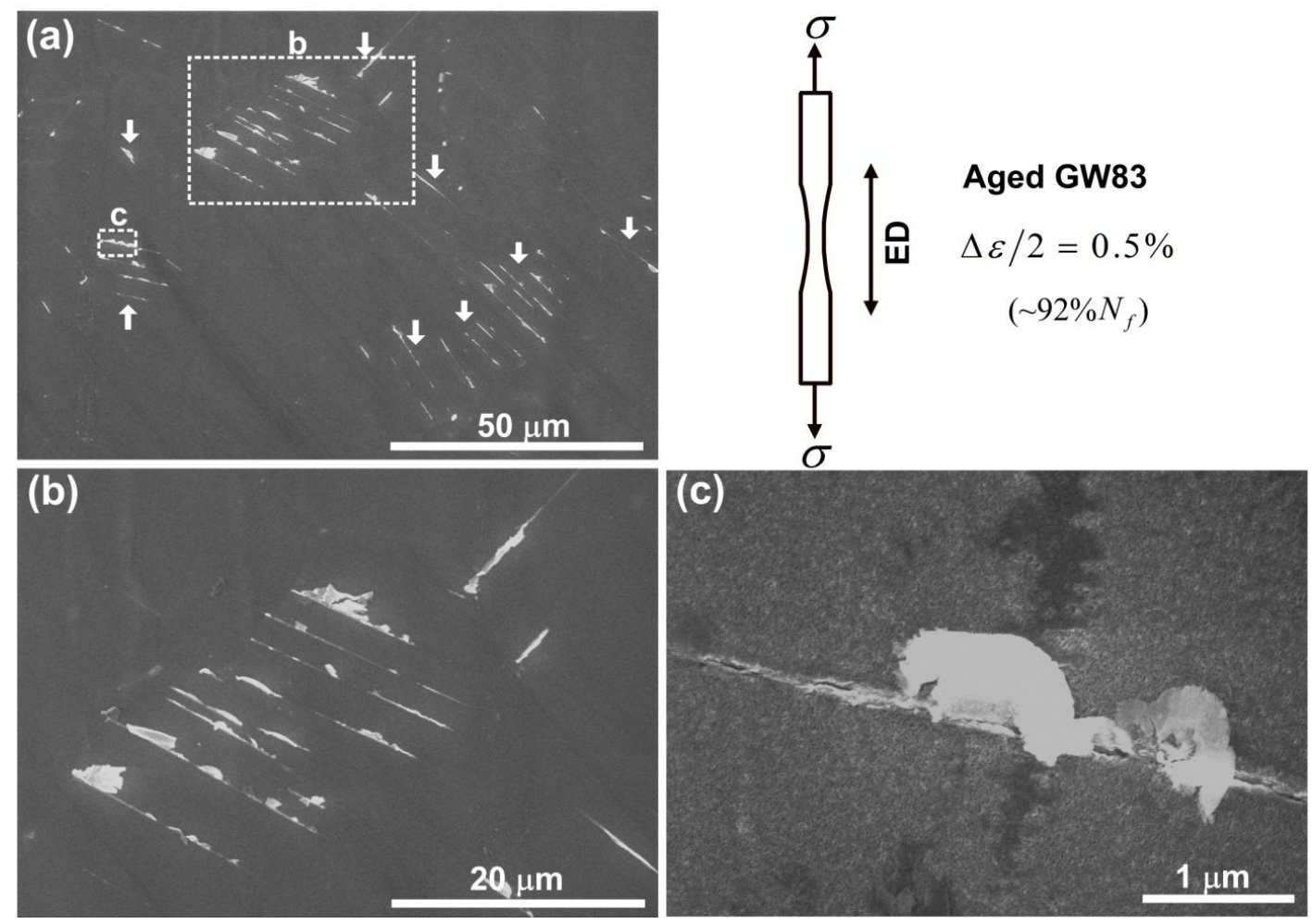

Fig. 9. SEM examinations of surface damage morphology: (a) aged GW83 alloy at 92\% fatigue life at $0.5 \%$ strain amplitude; (b) and (c) enlarged local areas in (a).

Fig. 9a shows the SEM examination of surface damage morphology for aged GW83 alloy at $92 \%$ fatigue life under a strain amplitude of $0.5 \%$ where slips dominate the cyclic plastic deformation. Fig. 9b and c are the enlarged local areas in Fig. 9a. From Fig. 9a and b, it can be seen that for aged GW83 alloy, many grains are covered with persistent slip bands (PSBs). However, the morphology of PSBs in aged GW83 is different from that in as-extruded GW83. It was reported [47] that for as-extruded GW83 alloy at a stain amplitude of $0.5 \%$, many grains were covered with straight and continuous PSBs. For aged GW83, the PSBs are fragmented by the precipitates. He [14] suggested that after peak aging treatment, the prismatic plate-shaped $\beta^{\prime}$ phase can be introduced to aged GW83 alloy. The PSBs in aged GW83 are unable to bypass the $\beta^{\prime}$ precipitation phases. As a result, short and fragmented PSBs are observed in Fig. 9a and b.

It was suggested [47] that for as-extruded GW83 alloy at a stain amplitude of $0.5 \%$, microcracks can be nucleated at PSBs and early crack growth often occurs along PSBs. With the resistance of $\beta^{\prime}$ phase in aged GW83, the initiation of microcracks can be impeded 
and the early crack growth occurring along PSBs can be resisted. The microcracks in aged GW83 can also be fragmented by the precipitates and the length of microcracks can be reduced, as shown in Fig. 9c. The result is a longer fatigue life in aged GW83 than as-extruded GW83 at the same strain amplitude of $0.5 \%$.

\section{Further Discussion}

Aging process can introduce precipitations in the extruded GW83 alloy. It was reported that the main precipitation phase in $\mathrm{Mg}-\mathrm{Gd}-\mathrm{Y}-\mathrm{Zr}$ alloy is the plate-shaped $\beta^{\prime}$ precipitate phase formed on prismatic planes of $\alpha-\mathrm{Mg}$ matrix phase $[12,14]$. The boundaries between the precipitate phases and the Mg matrix can block dislocation slips, resulting in a strengthening effect.

For the monotonic deformation, the aging process increases the elastic limit (microyielding stress) from 96MPa to $207 \mathrm{MPa}$ (see Table 1). For the GW83 alloy under investigation, basal slips are responsible for microyielding. Therefore, it can be concluded that the plate-shaped $\beta^{\prime}$ precipitate phases in aged GW83 strongly impede basal slips. This conclusion is consistent with the results reported by Agnew et al. [52]. It was suggested that similar plate-shaped precipitate phase formed on prismatic planes of $\alpha-\mathrm{Mg}$ matrix phase in a Mg-Y-Nd-Zr alloy could strongly impede basal slips. Moreover, the aging process also increases the macroyielding stress, the ultimate strength, and the fracture strength in tension by more than $100 \mathrm{MPa}$.

The fatigue experiments shown in Fig 7 a reveal that the strain amplitude corresponding to the kink point which represents a demarcation line of the involvement twinning-detwinning process is slightly increased from $0.75 \%$ to $0.8 \%$ by the aging process. Therefore, the aging treatment increases the activation stress of tension twinning of extruded GW83.

It was reported that for extruded ZK60 alloy, the aging process has a significant influence on monotonic deformation behavior but a marginal influence on the stabilized cyclic deformation and fatigue behavior [56]. There are two main differences in the aging effects between GW83 alloy and ZK60 alloy. The Mg-Zn precipitates in aged ZK60 have 
little effects on basal slips, while the precipitates in GW83 have a significant strengthening effect on basal slips. In addition, for the cyclic deformation, the stabilized hysteresis stress-strain loops of as-extruded and aged ZK60 are almost identical. The aging process has a marginal influence on the stabilized cyclic deformation and fatigue. In contrast, for GW83 alloy, when the strain amplitudes are above $0.5 \%$, the stress amplitudes of aged GW83 are obviously higher than that of as-extruded GW83 throughout the whole fatigue life. The aging process has a manifest strengthening effect on the cyclic deformation of GW83 alloy (see Fig. 5).

The different aging effects in GW83 and ZK60 alloy can be ascribed to the different precipitate shapes in these two Mg alloys. For aged GW83, the main precipitate phase is the plate-shaped precipitate formed on prismatic planes. For aged ZK60, the rod-like $\beta^{\prime}$ phase with its long axis normal to the basal plane provides a dominant strengthening effect. Nie [37] investigated the effects of precipitate shape and orientation on dispersion strengthening in $\mathrm{Mg}$ alloys by the Orowan equation calculation. It was suggested that for $\mathrm{Mg}$ alloys containing identical volume fractions and number densities of shear resistant precipitates per unit volume, the Orowan increments in the yield stress produced by prismatic plate-shaped precipitates are obviously larger than those produced by rod-like $[0001]_{\alpha}$ precipitates. The prismatic plate-shaped precipitate phase provides the most effective obstacle to basal dislocation slips $[14,37]$. Therefore, the influence of aging treatment on basal slips in GW83 alloy is more obviously than that in ZK60 alloy. The reason why aging process has a marginal influence on the stabilized cyclic deformation of ZK60 alloy but has an obviously strengthening effect on the cyclic deformation of GW83 alloy is also possibly due to the different precipitate phases. Dedicated microscopic observations such as TEM are required to further explore the role of precipitates in the cyclic deformation and fatigue behavior.

\section{Conclusions}

Monotonic tension, monotonic compression, and fully reversed strain-controlled cyclic deformation and fatigue experiments were conducted on aged GW83 alloy along the extrusion direction. The following conclusions can be drawn from the experimental study: 
1) The aging treatment $\left(225^{\circ} \mathrm{C}\right.$ for 10 hours (T5)) has a significant influence on mechanical properties under both monotonic tension and monotonic compression.

2) Basal slip-dominated microyielding occurs at a stress of approximately $96 \mathrm{MPa}$ for as-extruded GW83 and at a stress of approximately 207MPa for aged GW83, indicating that the precipitates introduced by aging process strongly impede basal slips.

3) More tension twins are observed in aged GW83 at the same tension/compression strain than in the extruded GW83, which can be attributed to the local stress concentrations around precipitates that may enhance initiation of twinning. However, the twin volume fraction of aged GW83 even at a strain of $5 \%$ is very small.

4) The aging treatment has a significant strengthening effect on the cyclic deformation of extruded GW83. The kink point in the strain-life curve demarcates the involvement of twinning-detwinning process in cyclic plastic deformation. The strain amplitudes at the kink points are $0.75 \%$ and $0.8 \%$, respectively, for ax-extruded and aged GW83, indicating an influence of the aging process on the activation of tension twinning.

5) When the strain amplitudes are below $0.8 \%$, aged GW83 alloy has a longer fatigue life than that of extruded GW83 alloy at an identical strain amplitude, which can be attributed to the fragmented PSBs and the inhibition of microcracks by the precipitates.

\section{Acknowledgements}

Jie Dong gratefully acknowledges the support by National Natural Science Foundation and Bao steel of China (No. U1360104). Yanyao Jiang thanks supports by the National Science Foundation (1126582), the US Department of Energy, Office of Basic Energy Sciences under Grant No. DE-SC0002144.

\section{References:}

[1] F.H. Froes, Mater. Sci. Eng. A., 184 (1994) 119-133.

[2] B.L. Mordike, T. Ebert, Mater. Sci. Eng. A., 302 (2001) 37-45.

[3] J.F. Nie, X. Gao, S.M. Zhu, Scripta Mater., 53 (2005) 1049-1053.

[4] L.L. Rokhlin, N.I. Nikitina, J. Alloys Compd., 279 (1998) 166-170. 
[5] I.A. Anyanwu, S. Kamado, Y. Kojima, Materials Transactions, 42 (2001) 1206-1211.

[6] L. Gao, R.S. Chen, E.H. Han, J. Alloys Compd., 481 (2009) 379-384.

[7] N. Stanford, Mater. Sci. Eng. A., 527 (2010) 2669-2677.

[8] N. Stanford, D. Atwell, M.R. Barnett, Acta Mater., 58 (2010) 6773-6783.

[9] N. Stanford, G. Sha, J.H. Xia, S.P. Ringer, M.R. Barnett, Scripta Mater., 65 (2011) 919-921.

[10] M. Yang, T. Guo, H. Li, Mater. Sci. Eng. A., 587 (2013) 132-142.

[11] M. Yang, Y. Zhu, X. Liang, F. Pan, Mater. Sci. Eng. A., 528 (2011) 1721-1726.

[12] S.M. He, X.Q. Zeng, L.M. Peng, X. Gao, J.F. Nie, W.J. Ding, J. Alloys Compd., 421 (2006) 309-313.

[13] S.M. He, L.M. Peng, X.Q. Zeng, W.J. Ding, Y.P. Zhu, Mater. Sci. Eng. A., 433 (2006) $175-181$.

[14] S.M. He, X.Q. Zeng, L.M. Peng, X. Gao, J.F. Nie, W.J. Ding, J. Alloys Compd., 427 (2007) 316-323.

[15] F.A. Mirza, D.L. Chen, D.J. Li, X.Q. Zeng, Materials \& Design., 46 (2013) 411-418.

[16] L. Zhang, J. Zhang, C. Xu, S. Liu, Y. Jiao, L. Xu, Y. Wang, J. Meng, R. Wu, M. Zhang, Materials \& Design., 61 (2014) 168-176.

[17] S.R. Agnew, M.H. Yoo, C.N. Tomé, Acta Mater., 49 (2001) 4277-4289.

[18] J. Bohlen, M.R. Nürnberg, J.W. Senn, D. Letzig, S.R. Agnew, Acta Mater., 55 (2007) 2101-2112.

[19] K. Hantzsche, J. Bohlen, J. Wendt, K.U. Kainer, S.B. Yi, D. Letzig, Scripta Mater., 63 (2010) 725-730.

[20] S. Sandlöbes, M. Friák, S. Zaefferer, A. Dick, S. Yi, D. Letzig, Z. Pei, L.F. Zhu, J. Neugebauer, D. Raabe, Acta Mater., 60 (2012) 3011-3021.

[21] S. Sandlöbes, S. Zaefferer, I. Schestakow, S. Yi, R. Gonzalez-Martinez, Acta Mater., 59 (2011) 429-439.

[22] J. Hadorn, K. Hantzsche, S. Yi, J. Bohlen, D. Letzig, J. Wollmershauser, S. Agnew, Metall and Mat Trans A, 43 (2012) 1347-1362.

[23] S.-Y. Chang, T. Nakagaido, S.-K. Hong, D.H. Shin, T. Sato, Materials Transactions, 42 
(2001) 1332-1338.

[24] J. Wang, J. Meng, D. Zhang, D. Tang, Mater. Sci. Eng. A., 456 (2007) 78-84.

[25] J.F. Nie, B.C. Muddle, Acta Mater., 48 (2000) 1691-1703.

[26] C. Antion, P. Donnadieu, F. Perrard, A. Deschamps, C. Tassin, A. Pisch, Acta Mater., 51 (2003) 5335-5348.

[27] G. Barucca, R. Ferragut, F. Fiori, D. Lussana, P. Mengucci, F. Moia, G. Riontino, Acta Mater., 59 (2011) 4151-4158.

[28] N. Tahreen, D.F. Zhang, F.S. Pan, X.Q. Jiang, C. Li, D.Y. Li, D.L. Chen, J. Alloys Compd., 615 (2014) 424-432.

[29] D. Ji, C. Liu, L. Tang, Y. Wan, C. Huang, Materials \& Design., 53 (2014) 602-610.

[30] N. Stanford, D. Atwell, A. Beer, C. Davies, M.R. Barnett, Scripta Mater., 59 (2008) $772-775$.

[31] L. Gao, H. Yan, J. Luo, A.A. Luo, R. Chen, Journal of Magnesium and Alloys, 1 (2013) 283-291.

[32] L. Shang, S. Yue, R. Verma, P. Krajewski, C. Galvani, E. Essadiqi, Mater. Sci. Eng. A., 528 (2011) 3761-3770.

[33] B. Langelier, S. Esmaeili, Mater. Charact., 101 (2015) 1-8.

[34] A. Styczynski, C. Hartig, J. Bohlen, D. Letzig, Scripta Mater., 50 (2004) 943-947.

[35] L. Wu, A. Jain, D.W. Brown, G.M. Stoica, S.R. Agnew, B. Clausen, D.E. Fielden, P.K. Liaw, Acta Mater., 56 (2008) 688-695.

[36] I.-H. Jung, M. Sanjari, J. Kim, S. Yue, Scripta Mater.

[37] J.F. Nie, Scripta Mater., 48 (2003) 1009-1015.

[38] H. Bayani, E. Saebnoori, Journal of Rare Earths, 27 (2009) 255-258.

[39] S.K. Chaudhuri, K. Nair, Materials Science and Engineering, 37 (1979) 159-164.

[40] X.N. Gu, W.R. Zhou, Y.F. Zheng, Y. Cheng, S.C. Wei, S.P. Zhong, T.F. Xi, L.J. Chen, Acta Biomaterialia, 6 (2010) 4605-4613.

[41] F.A. Mirza, D.L. Chen, D.J. Li, X.Q. Zeng, Mater. Sci. Eng. A., 575 (2013) 65-73.

[42] F.A. Mirza, D.L. Chen, D.J. Li, X.Q. Zeng, Mater. Sci. Eng. A., 588 (2013) 250-259.

[43] F. Mokdad, D.L. Chen, Materials \& Design, 67 (2015) 436-447. 
[44] M. Mokhtarishirazabad, M. Azadi, G. Hossein Farrahi, G. Winter, W. Eichlseder, Mater. Sci. Eng. A., 588 (2013) 357-365.

[45] M. Mokhtarishirazabad, S.M.A. Boutorabi, M. Azadi, M. Nikravan, Mater. Sci. Eng. A., 587 (2013) 179-184.

[46] N. Satyala, J.S. Krasinski, D. Vashaee, Acta Mater., 74 (2014) 141-150.

[47] F. Wang, J. Dong, M. Feng, J. Sun, W. Ding, Y. Jiang, Mater. Sci. Eng. A., 589 (2014) 209-216.

[48] F. Wang, J. Dong, Y. Jiang, W. Ding, Mater. Sci. Eng. A., 561 (2013) 403-410.

[49] R. Zhu, X. Cai, Y. Wu, L. Liu, W. Ji, B. Hua, Materials \& Design, 53 (2014) 992-997.

[50] F.A. Mirza, D.L. Chen, D.J. Li, X.Q. Zeng, Materials \& Design., 64 (2014) 63-73.

[51] J.D. Robson, N. Stanford, M.R. Barnett, Acta Mater., 59 (2011) 1945-1956.

[52] S.R. Agnew, R.P. Mulay, F.J. Polesak Iii, C.A. Calhoun, J.J. Bhattacharyya, B. Clausen, Acta Mater., 61 (2013) 3769-3780.

[53] Y. Xiong, Q. Yu, Y. Jiang, Mater. Sci. Eng. A., 546 (2012) 119-128.

[54] Q. Yu, J. Zhang, Y. Jiang, Q. Li, Int. J. Fatigue, 33 (2011) 437-447.

[55] Y. Xiong, Y. Jiang, Int. J. Fatigue, 64 (2014) 74-83.

[56] S. Dong, Y. Jiang, J. Dong, F. Wang, W. Ding, Mater. Sci. Eng. A., 615 (2014) 262-272. 